\title{
periferio
}

\section{"AÍ QUE ACABA MEU MAR DE ROSAS E COMEÇA O MEU CALVÁRIO": GÊNERO, SEXUALIDADE E O APRENDIZADO COM A DIFERENÇA ${ }^{1}$}

\author{
Dilton Ribeiro do Couto Júnior ${ }^{2}$ \\ Universidade do Estado do Rio de Janeiro - UERJ
}

\section{Resumo}

Este texto é fruto de pesquisa de doutorado recentemente concluída que investigou as marcas da abjeção de um grupo de jovens no Facebook. Esse grupo, constituído por jovens que se autodenominam gays, lésbicas e bissexuais, discute questões de gênero e sexualidade, com uma ênfase na crítica à heteronormatividade. A proposta deste texto é pensar uma educação com a diferença a partir do relato sobre relacionamentos amorosos de um dos membros do grupo. 0 relato do jovem Nectar (pseudônimo) no Facebook foi interpretado à luz das contribuições de autores que discutem as relações de poder, a heteronormatividade, a diferença, a produção dos estereótipos e das representações. Além disso, também busquei auxílio na metáfora do "armário" para compreender os gêneros e as sexualidades e, no decorrer das reflexões tecidas neste trabalho, aproprio-me da perspectiva queer como forma de desnaturalizar e ressignificar a matriz hegemônica da heterossexualidade. Considero que pensar uma educação com a diferença significa contestar a produção de uma diferença que identifica os sujeitos queer ("estranhos", "esquisitos") como "anormais" e colocar em xeque a universalização das singularidades, responsável pelo enquadramento dos sujeitos em categorias reconhecíveis e fixas que desconsideram as múltiplas formas de existência humana.

Palavras-chave: gênero; sexualidade; heteronormatividade; diferença

\footnotetext{
1 Uma versão preliminar desse texto foi apresentada no IV Seminário Enlaçando Sexualidades, realizado na Universidade do Estado da Bahia (UNEB).

2 Pós-doutorando no Programa de Pós-graduação em Educação da Universidade do Estado do Rio de Janeiro (ProPEd/UERJ), com bolsa CNPq. Membro do Grupo de Pesquisa Infância, Juventude, Educação e Cultura (IJEC) e do Grupo de Estudos em Gênero e Sexualidade e(m) Interseccionalidades (Geni). junnior_2003@yahoo.com.br
} 


\title{
periferio
}

\author{
"THAT IS WHEN MY BED OF ROSES ENDS AND MY CALVARY \\ STARTS": GENDER, SEXUALITY AND THE LEARNING WITH THE \\ DIFFERENCE
}

\begin{abstract}
This text is the result of a recently concluded doctoral research that investigated the marks of abjection of a group of young people on Facebook. This group, constituted of young people who identify as gay, lesbian and bisexual, discusses issues of gender and sexuality, with an emphasis on the critique of heteronormativity. The proposal of this text is to think of an education with the difference from a narrative on loving relationships from one of the members of the group. The story of young Nectar (pseudonym) on Facebook has been interpreted in the light of the contributions of authors who discuss the relations of power, heteronormativity, difference, the production of stereotypes and representations. In addition, I also sought aid in the metaphor of the "closet" to understand the genders and sexualities and, in the course of the discussions made in this work, the queer perspective is adopted as a way to denaturalize and rethink the hegemonic heterosexual matrix. I consider that to think of an education with the difference means to challenge the production of a difference that identifies the queer subjects ("strangers", "weirdoes") as "abnormal" and to question the universalization of the singularities, responsible for the framing of the subject in recognizable and fixed categories that disregards the multiple forms of human existence.
\end{abstract}

Keywords: gender; sexuality; heteronormativity; difference 


\section{periferio}

\section{INTRODUÇÃO}

"Quem defende a criança queer?" A partir dessa pergunta, Paul Beatriz Preciado (2013) coloca em debate o quanto muitas das crianças que fogem às expectativas sociais estipuladas pelas normas regulatórias de gênero encontram-se vulneráveis. Ao comentar sobre as experiências vivenciadas no âmbito familiar durante o período em que ainda vivia na Espanha, Preciado (2013) relata que desde que era bem pequeno seus pais já cumpriam a todo custo a função de garantir a supremacia da ordem heterossexual. Essa garantia das normas de gênero e sexualidade é firmada pela ótica heteronormativa, responsável pela formação dos sujeitos dentro do modelo hegemônico da heterossexualidade, supostamente superior e natural (MISKOLCl, 2009). Também faço minhas as palavras de Preciado (2013, p. 99), enfatizando a ideia de que "nós defendemos o direito das crianças a não serem educadas exclusivamente como força de trabalho e de reprodução. Defendemos o direito das crianças e adolescentes a não serem considerados futuros produtores de esperma e futuros úteros". Dessa forma, como abalar e ressignificar a lógica da força de trabalho e da reprodução dos sujeitos, buscando contribuições do aprendizado com a diferença para o campo de estudos de gênero e sexualidade na educação?

No contexto anglo-saxão, o emprego do termo queer é utilizado de forma pejorativa contra todos os sujeitos não-heterossexuais (LOURO, 2013). 0 outro sentido do termo, traduzido para a língua portuguesa, foi utilizado por Preciado (2013) no título de seu texto para referir-se à ideia de “diferente", “estranho", “esquisito". Louro (2013) caminha nessa mesma direção e encontra na palavra queer o sentido de "estranhar", de ir contra o "normal". Conforme reitera Miskolci (2013, p. 25), a teoria queer ${ }^{3}$ "é a recusa dos valores morais violentos que instituem e fazem valer a linha da abjeção,

\footnotetext{
${ }^{3}$ Foge dos limites desse texto realizar uma discussão mais detalhada da teoria queer, bem como de seus desdobramentos na pesquisa em gênero e sexualidade no Brasil. Para isso, ver os trabalhos de Ranniery (2017), Couto Junior (2016), Miskolci (2009) e Louro (2001).
} 


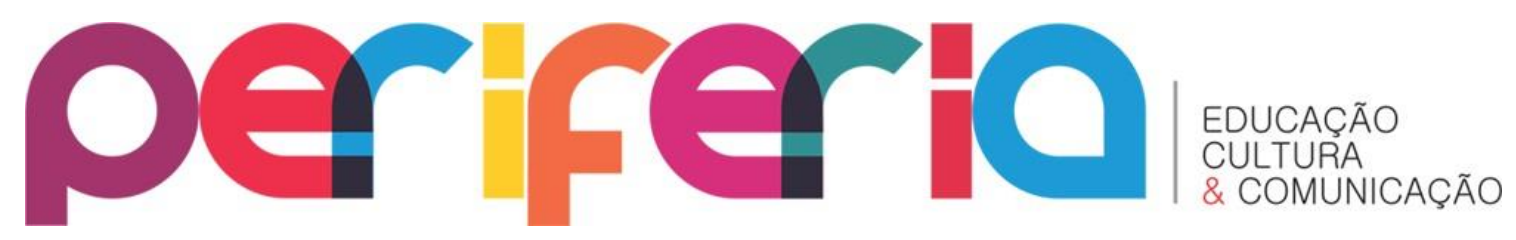

essa fronteira rígida entre os quais os que são socialmente aceitos e os que são relegados à humilhação e ao desprezo coletivo". Sendo assim, cabe indagar: como a teoria queer seria capaz de construir problematizações em torno da heteronormatividade compulsória da sociedade, promovendo uma nova compreensão sobre a diferença?

Louro (2009) revela que a heterossexualidade é uma construção social que exige investimentos e esforços criteriosamente elaborados para colocar em funcionamento sua normatização. As forças regulatórias que produzem as masculinidades e feminilidades sob a ótica heteronormativa afirma que a única forma de atração sexual legítima é entre um homem (pênis/masculino) e uma mulher (vagina/feminino). De acordo com Miskolci (2011), a ordem heteronormativa induz que todos os sujeitos, independente da orientação sexual, adotem o modelo hegemônico da heterossexualidade em suas vidas. Esse modelo, imposto e naturalizado há séculos, tentará de todas as formas silenciar e apagar a experiência de sujeitos que, de alguma forma, desviam-se da lógica binária de gênero. Os diversos xingamentos - “Bicha!”, “Sapatão!”, “Afeminado!”, dentre tantos outros - atribuídos aos sujeitos queer são imprescindíveis para reforçar e realimentar a heterossexualidade; não são xingamentos externos a heterossexualidade, mas a constituem (BENTO, 2011).

Este é o pano de fundo do presente artigo, fruto de pesquisa de doutorado recentemente concluída. 0 trabalho de campo, realizado entre 2013 e 2015, focalizou um grupo no Facebook de cerca de 80 jovens internautas que não se reconhecem no modelo hegemônico da heterossexualidade. Esse grupo constitui uma comunidade na referida rede social, discutindo questões de gênero e sexualidade, com uma ênfase na crítica à heteronormatividade. Em 2013, ano de entrada em campo, os sujeitos apresentavam idades que variavam entre 16 e 35 anos. A pesquisa adota o uso de pseudônimos, escolhidos pelos próprios sujeitos, porque reconhece a importância da autoria e a forma como os sujeitos autodenominam-se no texto escrito. 


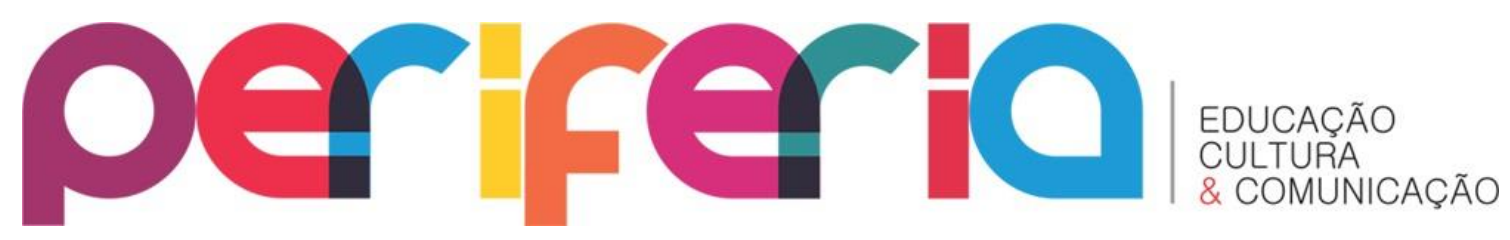

Mikhail Bakhtin (2011), um dos interlocutores privilegiados para subsidiar teórico e metodologicamente a relação com os sujeitos no estudo de campo, discute a necessidade absoluta do outro no processo da comunicação dialógica através da premissa de que pesquisador e sujeitos produzem, juntos, novas percepções sobre o mundo na medida em que cada um afeta e é afetado pelo outro. Sobre a ótica bakhtiniana, Bezerra (2012, p. 194) aponta que “o ‘eu’ não pode ser solitário, um ‘eu’ sozinho, pois só pode ter vida real em um universo povoado por uma multiplicidade de sujeitos interdependentes e isônomos”. Essa orientação teórico-metodológica pressupõe a comunicação dialógica no encontro com o outro, concebendo pesquisador e sujeitos como parceiros ativos na relação e produção colaborativa do conhecimento ${ }^{4}$.

Diante do exposto, o objetivo proposto neste texto é pensar uma educação com a diferença a partir do relato de um dos integrantes do grupo, o jovem Nectar. Ao ser convidado para narrar sobre seus relacionamentos amorosos, o jovem expõe no Facebook questões importantes que possibilitaram refletir sobre gênero e sexualidade e, mais especificamente, a heteronormatividade. 0 relato dele é interpretado à luz das contribuições de autores que discutem as relações de poder (SILVA, 2005, 2013; BHABHA, 1998; BACCHETTA, 2009; FOUCAULT, 1995, 2004), a produção dos estereótipos e das representações (DELEUZE, 2000; BHABHA, 1998), a heteronormatividade (BUTLER, 1993; MISKOLCI, 2009) e a diferença (DELEUZE, 2000; SOARES, 2013; LOURO, 2011). Além desse embasamento teórico, também busco auxílio na metáfora do "armário" (SEDGWICK, 2007) para compreender os gêneros e as sexualidades e, no decorrer do trabalho, aproprio-me da perspectiva queer (LOURO, 2013; PRECIADO, 2013; MISKOLCI, 2005, 2011) como forma de refletir sobre a desnaturalização e ressignificação da matriz hegemônica da heterossexualidade.

\footnotetext{
${ }^{4}$ Também foge aos limites desse texto explorar mais detalhadamente as implicações da pesquisa online na relação com o outro. Para uma discussão mais aprofundada sobre a pesquisa online subsidiada pelas contribuições bakhtinianas, ver os trabalhos de Couto Junior (2013), Couto Junior e Oswald (2016) e Couto Junior, Ferreira e Oswald (2017).
} 


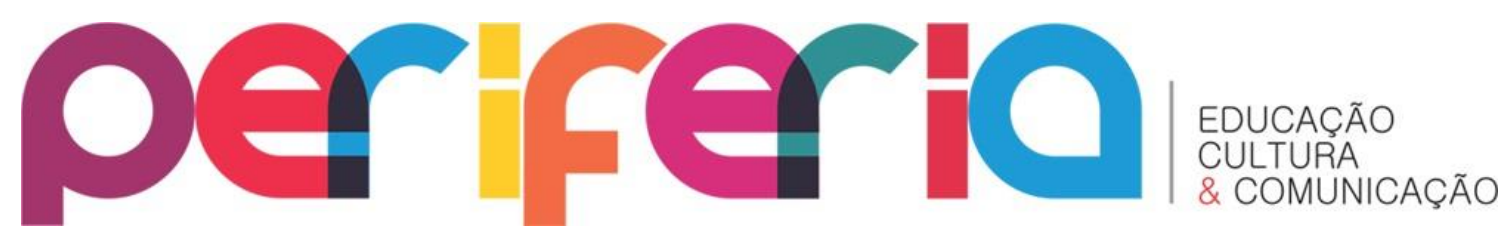

"E É AÍ QUE [...] COMEÇA O MEU CALVÁRIO": DIFERENÇA, ESTEREÓTIPO E A REPRESENTAÇẪO EM QUESTÃO

O representante diz: “Toda a gente reconhece que...", mas há sempre uma singularidade, não representada, que não reconhece, porque precisamente ela não é toda a gente ou não é o universal. "Toda a gente" reconhece o universal, pois ele próprio é o universal, mas o singular não o reconhece, isto é, a profunda consciência sensível que no entanto deve arcar com as consequências. A infelicidade de se falar não está em falar, mas em falar pelos outros ou representar alguma coisa. A consciência sensível [...] obstina-se" (DELEUZE, 2000, p. 116, grifos meus).

A perspectiva pós-estruturalista compreende que a produção da "diferença" se constitui em conexão com as relações de poder (SILVA, 2005). Quem "representa" quem no contexto das dinâmicas sociais que coloca determinados grupos sociais na condição de "representantes" e de "representados"? Será que, efetivamente, todos sentem-se representados? A busca incessante pela produção das classificações identitárias e o enquadramento dos sujeitos em categorias sociais universais impede 0 reconhecimento e a legitimação da diferença. Ao mesmo tempo em que são produzidas práticas sociais condizentes com a naturalização da heterossexualidade, criam-se processos excludentes contra os sujeitos que não se identificam com essas mesmas práticas. Foucault (1995, p. 239) aposta na ideia de não "descobrir o que somos, mas recusar o que somos. Temos que imaginar e construir o que poderíamos ser para nos livrarmos deste 'duplo constrangimento' político, que é a simultânea individualização e totalização própria às estruturas do poder moderno". Isso significa recusar formas préconcebidas de compreender os sujeitos, engajando-nos em novas estratégias de resistência contra o controle que alguns grupos exerce sobre outros.

$\mathrm{Na}$ perspectiva foucaultiana, a noção de poder não apresenta "uma forma dada. Isso não significa que o poder seja universal, constante, imutável ou uniformemente organizado no tempo e no espaço; se fosse assim, produziria condições, sujeitos, objetos e condutas idênticas em todo lugar, a 


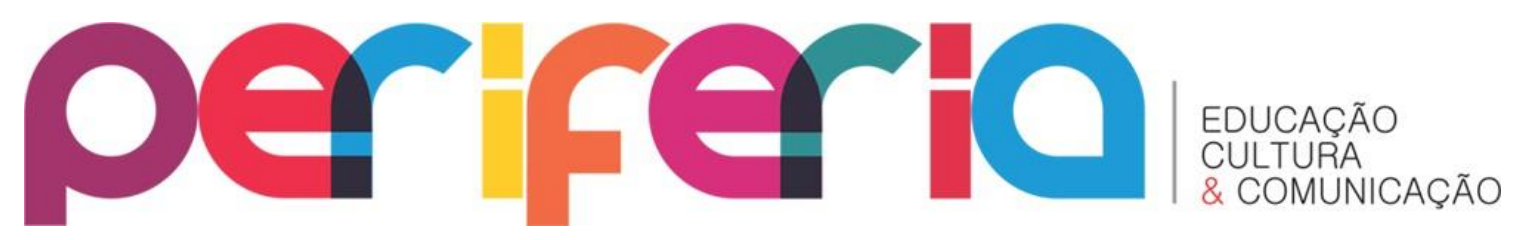

todo momento" (BACCHETTA, 2009, p. 56). Sempre presente nas relações humanas, o poder é instável e reversível quando existe o mínimo de liberdade para que os sujeitos encontrem estratégias de resistência (FOUCAULT, 2004). No contexto dessas relações, compreendo a necessidade de criação de políticas públicas sintonizadas com os esforços das epistemologias queer; políticas que estejam dispostas a contestar e problematizar os privilégios concebidos e legitimados a alguns grupos sociais, focalizando também na produção das "experiências subjetivas marcadas pela abjeção" (MISKOLCI, 2011, p. 54). Vale ressaltar que a abjeção, espaço relegado a todos os sujeitos consideramos como ameaça ao funcionamento da ordem social e política, constitui-se como a experiência de ser repugnado socialmente (MISKOLCI, 2013).

Ainda é predominante uma concepção de mundo que prima pela "lógica binária pela qual o corpo, identificado como macho ou como fêmea, determina o gênero (um de dois gêneros possíveis: masculino ou feminino) e leva a uma forma de desejo (especificamente, o desejo dirigido ao sexo/gênero oposto)" (LOURO, 2013, p. 82-83). A organização social dentro de uma perspectiva binária (homem/mulher, homo/heterossexual) reflete as hierarquias de gênero, demarcando e naturalizando os sujeitos ditos "normais" e os sujeitos "diferentes" (MISKOLCI, 2011). Somando-se a isso, as relações de poder que produzem e legitimam determinadas formas de ser e estar no mundo colocam as chamadas "minorias sexuais" na condição de sujeitos abjetos. Como modificar esse cenário e ressignificar as formas de conceber os gêneros e as sexualidades que não se identificam com o modelo hegemônico da heterossexualidade?

Deleuze (2000, p. 116, grifos meus) defende que a universalização das singularidades humanas apresenta consequências sociais. Reforçando os dizeres do filósofo, é "a profunda consciência sensível que no entanto deve arcar com as consequências". No campo de estudos de gênero e sexualidade na educação, as graves consequências sociais engendradas pela ótica heteronormativa torna imprescindível buscar estratégias de resistência contra 


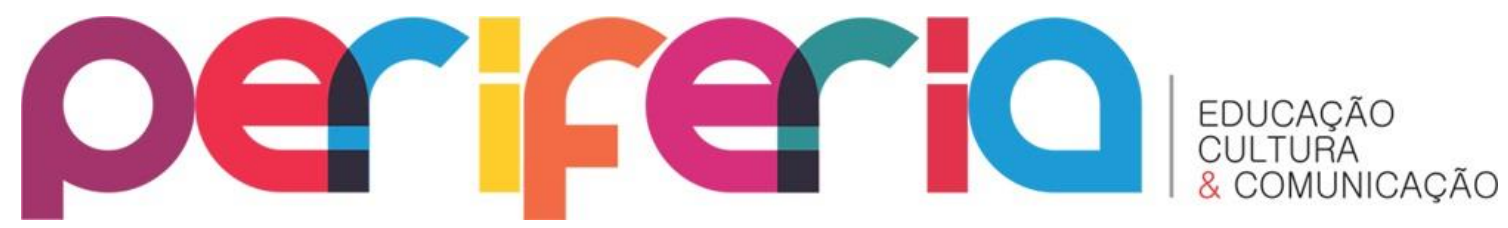

a tentativa de universalizar as singularidades humanas, contestando a produção de discursos em sintonia com as representações hegemônicas. Seria preciso ressaltar que essas consequências sociais colocam determinados sujeitos na condição de “diferentes”, uma diferença que desqualifica, desvaloriza e torna esses sujeitos “indesejáveis”. A seguir, parte do relato do jovem Nectar compartilhado no Facebook torna possível discutir gênero e sexualidade dentro do contexto da diferença, do estereótipo e da representação:

Nectar: acho que eu nunca falei sobre isso, então será uma verborréia... então... meu primeiro beijo, foi triplo, com uma menina e um menino, numa festa de família, e as crianças saíram gritando contando pra todo mundo e posteriormente me viram de pegação nas matinês da vida e acabaram sabendo que eu tinha transado com o filho da minha babá (o primeiro e o melhor!), então todo mundo sabe que eu pego rapazes. até uns 15-16 anos eu ficava tanto com mulheres quanto com homens, e aos 17 me apaixonei... por uma mulher, que me trocou... desiludido (na verdade ainda apaixonado, maybe, até hoje) parei de ficar com mulheres e aí eu peguei gosto pela coisa e passei a adentrar mais no 'mundo gay'... meus familiares nunca me perguntaram se eu era gay e eu também nunca vi a necessidade de contar, nem para os meus pais, sobre a minha vida sexual... mas se eu tivesse que contar, acho que não haveria problemas de aceitação, tenho um primo assumidamente gay e uma prima que se diz bissexual... minha família é tradicional e conservadora, mas dentro de suas próprias tradições, e a 'educação sexual' é uma delas, que inclusive incentiva a liberdade sexual (minha tia tem a máxima: 'todo ser humano é capaz de proporcionar prazer a outro ser humano')... por isso, eu apenas sigo a vida, sem me esconder, mas também sem levantar bandeira. até porque se eu fosse me rotular não seria como gay porque eu também sinto atração por mulheres... nessa tal de 'educação sexual' eu aprendi muitas coisas sobre sexo e sobre pensar sobre sexo, $e$ uma dessas coisas é que sexo e afetividade podem andar juntos, mas não são siameses, por isso, eu prefiro pensar que sou bissexual e homoafetivo, porque hoje eu não teria um relacionamento com mulheres. E é aí que acaba meu mar de rosas e começa o meu Calvário...

0 relato de Nectar apresenta inúmeras questões que merecem ser destacadas e refletidas. Primeiramente, é muito significativo o fato de que 


\section{periferio}

"as crianças saíram gritando contando pra todo mundo" quando o jovem beijou uma menina e um menino durante o que ele denominou de "festa de família". O que motiva a ação de sair correndo e enunciar o ocorrido? Concordo com Deleuze (2000, p. 115), para quem a diferença precede a identidade, mas quando foi "colocada à força numa identidade prévia, quando foi colocada nesse declive do idêntico que a leva necessariamente para onde a identidade quer e a reflectir-se onde a identidade quer, isto é, no negativo", a diferença passa a ser "aprisionada" pela identidade. Dessa forma, a "festa de família" constitui-se como um espaço de denúncia de um grupo de crianças sobre outro, revelando que determinadas práticas sociais afetivas não condizem com a identidade de gênero de Nectar, que se torna marcado por uma diferença cujo valor negativo é reforçado pela ótica heteronormativa. Como subverter essas práticas preconceituosas e discriminatórias, problematizando e contestando a produção das identidades e a normatização da diferença? Caminhando na ótica deleuziana, Gil (2000, p. 12) também se lança no desafio de questionar a relação entre identidade, diferença e negação, propondo a seguinte pergunta: "como alcançar essa esfera em que a diferença está em primeiro lugar relativamente à identidade (e à negação), se é verdade que somos obrigados a partir sempre destas oposições categoriais?”. De acordo com Deleuze (2000), seria preciso um esforço para compreender a diferença para além da negatividade.

Bhabha (1998, p. 107) reforça também que o “corpo está sempre simultaneamente (mesmo que de modo conflituoso) inscrito tanto na economia do prazer e do desejo como na economia do discurso, da dominação e do poder". A naturalização e a normatização das formas com as quais desfrutamos e buscamos os desejos e os prazeres corporais produz, ao mesmo tempo, sujeitos socialmente reconhecidos como "normais" e aqueles marcados como "diferentes". Os discursos demarcam as fronteiras do sexo e, de acordo com a perspectiva pós-estruturalista, as diferenças são produzidas nas relações de poder, no qual o valor sociocultural atribuído ao "diferente" é sempre inferior ao valor atribuído ao "não-diferente" (SILVA, 2005). Essas 


\section{periferio}

fronteiras discursivas estiveram bem demarcadas durante a "festa de família" narrada por Nectar, bem como nas festas diurnas ("matinês"), segundo o jovem: "me viram de pegação nas matinês da vida e acabaram sabendo que eu tinha transado com o filho da minha babá (o primeiro e o melhor!)". Compreendendo a inscrição do corpo na economia do prazer, desejo, discurso, dominação e poder (BHABHA, 1998), é preciso considerar que, na visão heteronormativa, o preconceito e a discriminação não recai sobre o "acabaram sabendo que eu tinha transado", mas no fato de que os sujeitos identificam-se com o mesmo gênero.

Além disso, algumas reflexões merecem destaque a partir da afirmação de Nectar a seguir: "meus familiares nunca me perguntaram se eu era gay". A primeira delas caminharia numa direção que compreende a não necessidade de uma resposta afirmativa ("sim, sou gay") porque, a priori, a ótica heteronormativa entende que todos os seres humanos com pênis deveriam, necessariamente, se relacionar sexualmente entre sujeitos com vaginas. Outra reflexão diz respeito à hipótese de que se os pais de Nectar nunca perguntaram é porque já sabem ou temem saber. Somando-se a isso, talvez o mais interessante seja perceber o quanto há uma certa "precaução" quando o assunto em pauta são as sexualidades que fogem ao modelo heterossexual. Concordo com Foucault (1997, p. 138), para quem defende um modo de vida compartilhado entre diferentes indivíduos, cujas intensas relações não necessariamente "se assemelham às que estão institucionalizadas. [...] Para ser 'gay', penso eu, é não se identificar com os traços psicológicos e as máscaras visíveis do homossexual mas tentar definir e desenvolver um modo de vida ${ }^{5}$ ". Compreendendo que há muitos modos de vida que diferem dos valores socioculturais da familiar heterossexual cristã - como a própria poligamia e as relações homoafetivas para citar algumas -, quais outras

\footnotetext{
${ }^{5}$ Tradução de: "not resembling those that are institutionalized. It seems to me that a way of life can yield a culture and an ethics. To be 'gay,' I think, is not to identify with the psychological traits and the visible masks of the homosexual but to try to define and develop a way of life" (FOUCAULT, 1997, p. 138).
} 


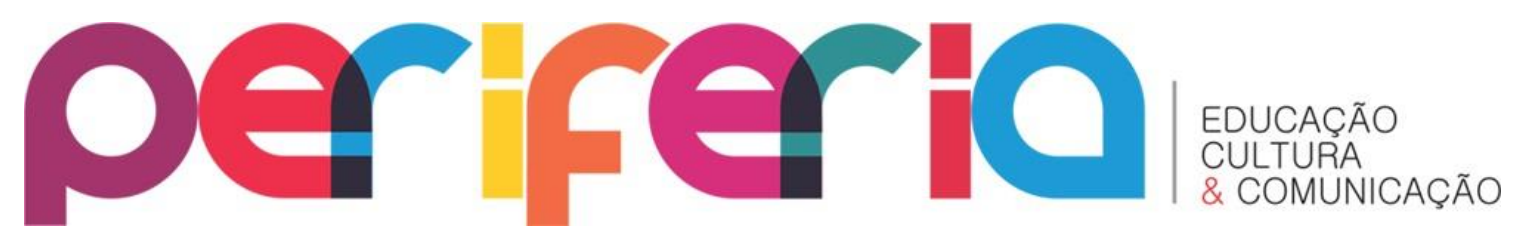

possibilidades amorosas e arranjos familiares vêm se constituindo na contemporaneidade?

Ainda que no contexto familiar do jovem o "ser gay" seja tão reconhecido e legitimado quanto o "ser hetero", Nectar reforça a hierarquia das sexualidades e entra no jogo das relações de poder quando afirma que: "se eu tivesse que contar, acho que não haveria problemas de aceitação". Essa ideia caminha na mesma linha de pensamento elencada por Silva (2005), ao mostrar que os princípios de tolerância, respeito e convivência harmônica entre as culturas não são suficientes para desestruturar as relações de poder responsáveis pela produção de uma diferença que desqualifica e desvaloriza o sujeito. De acordo com o autor,

Apesar de seu impulso aparentemente generoso, a ideia de tolerância, por exemplo, implica também uma certa superioridade do que mostra "tolerância". Por outro lado, a noção de "respeito" implica um certo essencialismo cultural, pelo qual as diferenças culturais são vistas como fixas, como já definitivamente estabelecidas, restando apenas "respeitálas" (SILVA, 2005, p. 88, grifos meus).

Valorizar e reconhecer a "diferença” não é suficiente para combater os processos discriminatórios e preconceituosos. A mera valorização e “aceitação” de uma diferença que reforça a matriz heterossexual cria novos mecanismos de exclusão. O que precisa ser contestada é a matriz heterossexual, responsável pela regulação das condutas sociais, pois se apenas o discurso dessa valorização recai sobre as pessoas “diferentes" é porque aqueles ditos como “normais” já são valorizados. Como aponta Silva (2013, p. 81-82, grifos meus), a diferença nunca é inocente, mas carrega inúmeras “marcas da presença do poder: incluir/excluir ('estes pertencem, aqueles não'); demarcar fronteiras ('nós' e 'eles'); classificar ('bons e maus'; 'puros e impuros'; 'desenvolvidos e primitivos'; 'racionais e irracionais'); normalizar 'nós somos normais; eles são anormais')". Essas marcas são claramente visíveis e constantemente naturalizadas nos discursos da ótica hegemônica da heterossexualidade. Quem determina os critérios de incluir/excluir? Como as 


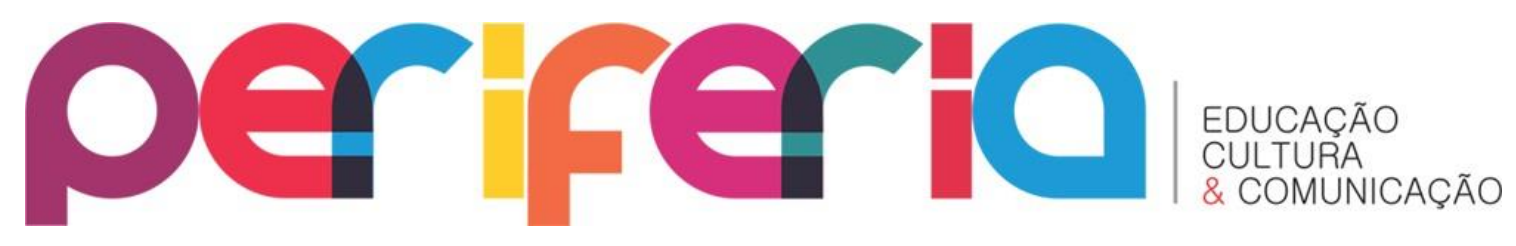

fronteiras do sexo são demarcadas? Quais as repercussões sociais engendradas pelas relações de poder que hierarquizam os gêneros e as sexualidades? Como pensar para além da classificação e da hierarquização? E, por fim, quem precisa de classificação?

A partir da afirmação "toda a gente sabe...", Deleuze (2000, p. 227, grifos meus) ressalta que "há alguém, mesmo que seja apenas um, com a modéstia necessária, que não chega a saber o que toda a gente sabe e que nega modestamente o que se julga ser reconhecido por toda a gente". 0 autor continua e mostra que este alguém "não se deixa representar e que também não quer representar quem quer que seja" (p. 227). Ainda que muitos sujeitos não identifiquem-se com as inúmeras representações sociais que emergem cotidianamente no contexto das relações de gênero e sexualidade, a dificuldade da autodenominação de Nectar traz a oportunidade para que sejam refletidos as identidades e os estereótipos: "se eu fosse me rotular não seria como gay porque eu também sinto atração por mulheres". Os processos identitários ancorados na perspectiva binária (homem/mulher, homo/heterossexual, dentre outros) não só são insuficientes para abarcar os modos de subjetivação dos sujeitos, mas atribuem negativamente valores socioculturais sobre as sexualidades que fogem à matriz heterossexual. Dessa forma, considero imprescindível a interlocução com os estudos queer, que propõe a desconstrução das categorias identitárias e "trazem à luz as estruturas de poder e dominação que estabelecem os padrões de aceitabilidade e rejeição de identidades. Afinal, identidades (estigmatizadas) nada mais são do que construções de diferenças a partir de comportamentos e estilos de vida" (MISKOLCl, 2005, p. 33).

É a necessidade do outro em nos classificar, ao mesmo tempo em que nós também sentimos o desejo de conhecer o outro pela referência da sexualidade, que caímos na armadilha do enquadramento e, consequentemente, da criação de estereótipos atribuídos aos sujeitos. Para Bhabha (1998, p. 117, grifo do autor), o estereótipo é "uma falsa representação de uma dada realidade. É uma simplificação porque é uma 


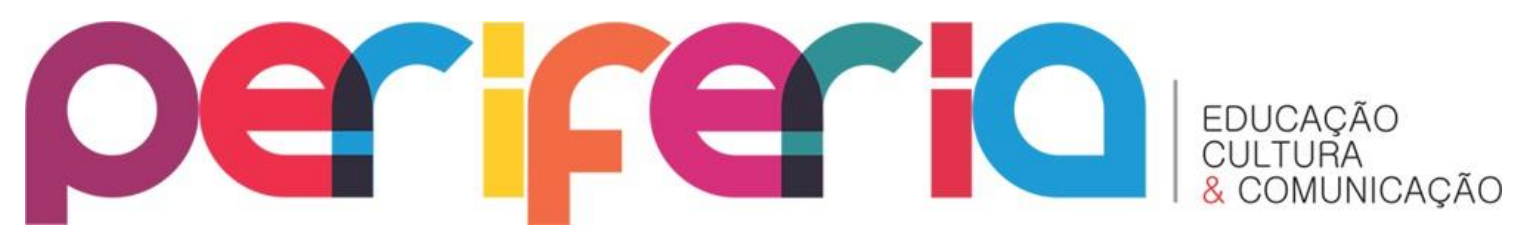

forma presa, fixa, de representação que, ao negar o jogo da diferença (que a negação através do Outro permite), constitui um problema para a representação do sujeito". Portanto, ao desconsiderarmos a constituição dos processos de subjetivação, nos restaria apenas assumir possibilidades presumíveis e pré-determinadas de viver e de explorar os diferentes prazeres corporais, uma vez que a forma estereotipada de conhecer o outro "não é capaz de oferecer um porto seguro de identificação devido ao processo de conhecimento que the é inerente (ambivalente, complexo, contraditório, ansioso e afirmativo ao mesmo tempo)" (SOARES, 2013, p. 91).

Nectar utiliza a metáfora do Calvário (nome dado à colina na qual Jesus foi crucificado) para trazer a tona a ideia da dor e do sofrimento em não reconhecer-se no modelo hegemônico da heterossexualidade: "prefiro pensar que sou bissexual e homoafetivo, porque hoje eu não teria um relacionamento com mulheres. E é aí que acaba meu mar de rosas e começa o meu Calvário...". Esse infortúnio narrado pelo jovem traz as marcas do preconceito e da discriminação, muito presentes nas vidas cotidianas de sujeitos cujas representações são estigmatizadas e marcadas pela abjeção. 0 caminho encontrado por ele como estratégia de resistência é seguir a vida, "sem me esconder, mas também sem levantar bandeira". Frente a isso, percebo um caráter ambivalente nos dizeres do jovem: ao mesmo tempo em que Nectar afirma não se "esconder [dentro do armário]", a ideia de não "levantar bandeira" constituir-se-ia como uma forma de tornar-se invisível e silenciado frente às práticas regulatórias que legitimam a produção dos discursos homofóbicos. De qualquer forma, não há como desconsiderar que o "armário" é uma característica da vida social das pessoas gays, constituindose como uma estratégia pessoal indicativa da homofobia (SEDGWICK, 2007).

Defendo a perspectiva das epistemologias queer, que prima por uma nova crítica política: "ao invés de criticar ou focar apenas em manifestações de homofobia para mostrar que se baseiam em visões incorretas ou mentirosas, os [estudos] queer preferem apontar para as estratégias de legitimação heterossexual” (MISKOLCl, 2011, p. 55, grifo meu). Diante disso, o 


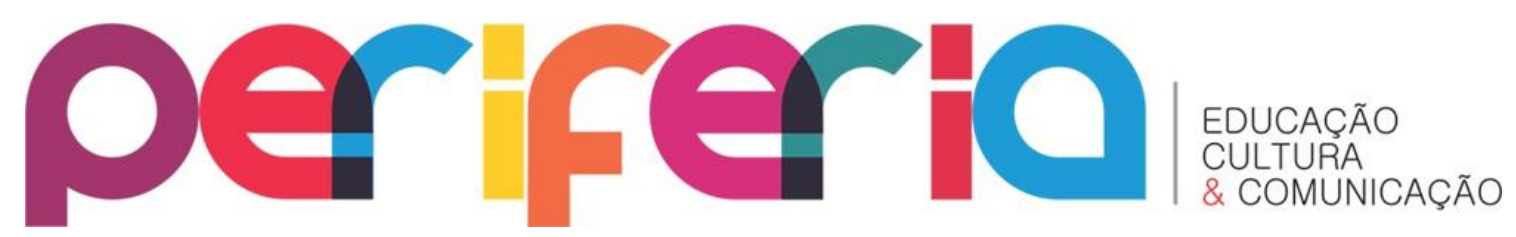

que torna a necessidade encontrada por muitos jovens brasileiros hoje para evitar “levantar bandeira"? Quais "bandeiras” são legitimadas e quais ainda enfrentam resistências sociais para ser levantadas? A meu ver, seria preciso compreender os privilégios que determinadas “bandeiras" adquirem no que se refere ao reconhecimento e legitimação social e como a diferença é produzida nesse processo.

\section{"NÃO CONSEGUE SE ASSUMIR NEM PRA SI MESMO": DO CALVÁRIO À METÁFORA DO “ARMÁRIO”}

Muitas feministas vêm optando por "mover-se além dos discursos de seus próprios apagamentos e des-identificações dominantes, que é resistir ao aprisionamento do 'Eu não sou...'. Elas têm procurado, também, imaginar formas de autoria, possibilidades auto-identificatórias do 'Eu / Você / Nós poderíamos ser'” (BACCHETTA, 2009, p. 62). Enquanto a ótica heteronormativa propõe o silenciamento de determinadas formas de ser e estar no mundo, inúmeros movimentos sociais buscam construir e planejar estratégias que garantam a possibilidade de contestar os privilégios da heterossexualidade e, ao mesmo tempo, compreender as singularidades humanas nas diversas instâncias sociais. A partir da formulação de uma pergunta, Guattari e Rolnik (1996, p. 66, grifos meus) mostram que a produção das subjetividades não comporta normas regulatórias: "será que a relação fundadora do ego, aquilo que nos dá o sentimento de sermos nós mesmos, está em nossa obediência ao código de uma microssociedade ou às leis de uma sociedade?". Somando-se a isso, como subverter e desconstruir as normas regulatórias? Como problematizar determinados processos identitários que corroboram a universalização das singularidades humanas?

A seguir, Nectar prossegue com o seu relato no Facebook e traz novos elementos para pensar sobre a metáfora do "armário":

Nectar: [...] o tempo passou e foi aí que eu reencontrei um dos corações partidos (que na verdade nem tava partido, ele 


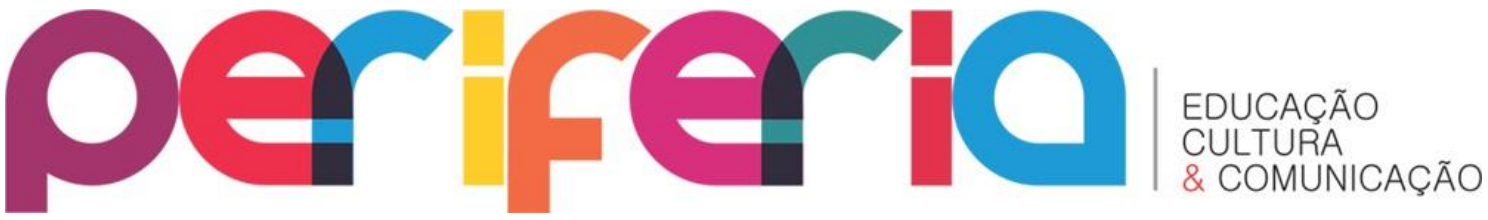

tinha levado de boa)... a gente começou do zero, conversamos bastante, transamos (porque é sempre bom e Roma não foi construída em um dia só hahaha), mas também saímos pra jantar, saímos com amigos e todas essas coisas... e puff! me apaixonei de novo! mas dessa vez eu tinha um coração e pior! dessa vez eu fui correspondido! e fomos felizes para sempre... só que não! (tem que lembrar que é o Calvário) ele é enrustido... a família não é homofóbica, os amigos não são homofóbicos, mas pelo que parece, ele não se aceita... ele tentou anos namorar com mulheres, mas não conseguiu ficar feliz, aí resolveu transar com homens e tá de boa... mas não consegue se assumir nem pra si mesmo... eu tava tranquilo, já fiquei com muito enrustido e hetero, e pra mim não tem problema nenhum ficar no armário e achava que era só dar tempo ao tempo... até que um dia a gente foi pra balada com uns amigos dele e ele me obrigou a ficar com um amigo dele que todo mundo sabe que é gay... pensei que ele tinha fetiche em ser voyeur, mas era só pra ninguém desconfiar que na verdade eu estava acompanhando ele... nem fiquei com raiva, pq o amigo era um goxtoso, mas profundamente triste... e como eu amo mais que tudo a minha liberdade, resolvi abandonar essa relação sem futuro, pelo menos até ele tomar uma atitude... mesmo tendo certeza que ele é o amor da minha vida... fim.

Louro (2011, p. 87) apresenta algumas provocações interessantes: “Como se reconhecer em algo que se aprendeu a rejeitar e a desprezar? Como, estando imerso/a nesses discursos normalizadores, é possível articular sua (homo)sexualidade com prazer, com erotismo, com algo que pode ser exercido sem culpa?". Os dizeres de Louro (2011) e as palavras de Nectar me ajudam a compreender que a "culpa" que muitos jovens carregam estaria diretamente relacionada à permanência no "armário": "um dia a gente foi pra balada com uns amigos dele e ele me obrigou a ficar com um amigo dele que todo mundo sabe que é gay... pensei que ele tinha fetiche em ser voyeur, mas era só pra ninguém desconfiar que na verdade eu estava acompanhando ele..." . Compreendo o "armário" enquanto um dispositivo que regula a vida de pessoas gays e lésbicas (SEDGWICK, 2007), cabe questionarmos "até quando os jovens que fogem à matriz heterossexual ainda precisarão se sentir 'culpados' e permanecer no 'armário', deixando de desfrutar dos desejos e dos prazeres corporais ditos 'proibidos', (COUTO JUNIOR, 2014, p. 101). Dessa 


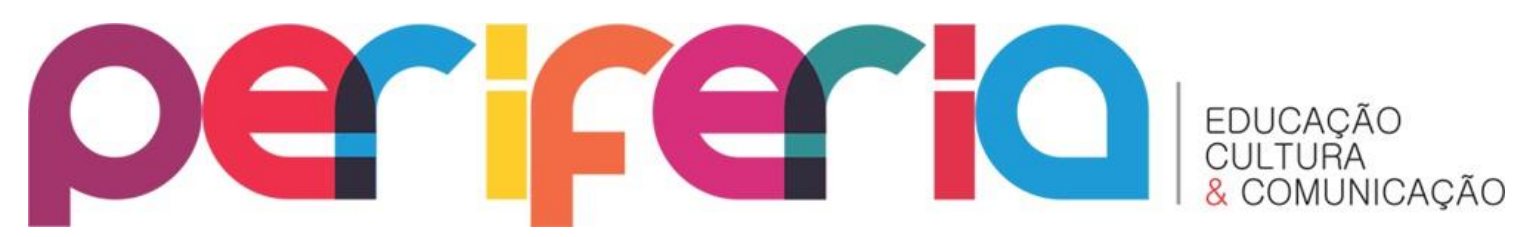

forma, defendo que os significantes "gay" e “lésbica”, para citar alguns, necessitam de novas ressignificações na vida social com o objetivo de que produzam sentidos interessantes e prazerosos e, com isso, propiciar que os estigmas sociais atribuídos aos sujeitos não-heterossexuais sejam minimizados (BRITZMAN, 1996). Se um dos "corações partidos" de Nectar é "enrustido", "não se aceita", "não consegue se assumir nem para si mesmo", seria preciso ressignificar os discursos preconceituosos e discriminatórios responsáveis pela produção de uma representação depreciativa atribuída aos sujeitos nãoheterossexuais.

Quem defende os direitos dos sujeitos queer? Se Preciado (2013) nos ensinou a necessidade de um olhar sensível diante dos discursos extremamente violentos praticados contra as crianças queer, Sedgwick (2007, p. 22) também pontua a necessidade de compreender que a presença do “armário" ainda é muito comum na vida contemporânea: “há poucas pessoas gays, por mais corajosas e sinceras que sejam de hábito, por mais afortunadas pelo apoio de suas comunidades imediatas, em cujas vidas o armário não seja ainda uma presença formadora". O que podemos aprender sobre gênero e sexualidade com o “armário"? O que ele representa? Ainda que seja uma estratégia legítima de resistência às práticas sociais homofóbicas, é preciso considerar também que o "armário" é uma forma de silenciar determinadas formas de ser e estar no mundo, adequando os sujeitos a padrões heteronormativos.

Pensar uma educação com a diferença, à luz das inspirações da teoria queer, talvez seja hoje um dos caminhos a ser trilhado com o objetivo de desnaturalizar e desestabilizar a matriz hegemônica da heterossexualidade. De acordo com Miskolci (2011, p. 54, grifo meu), "ao contrário da antiga política gay e lésbica liberacionista que pregava o sair do armário como libertação, uma política queer foca nas relações de poder e nas fissuras dentro de regimes que permitiriam a constituição de formas de resistência”. A partir das experiências sociais marcadas pela abjeção, os sujeitos queer 


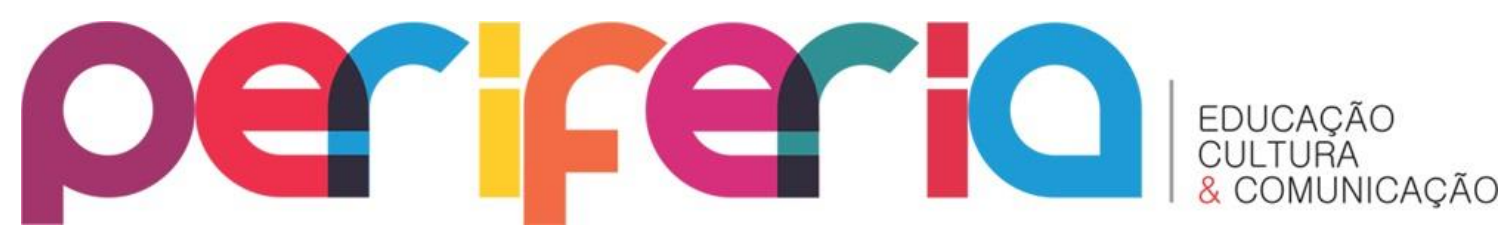

buscam estratégias para resistir e lutar contra a naturalização e a normatização do modelo heterossexual.

\section{APRENDENDO COM A DIFERENÇA: BREVES APONTAMENTOS FINAIS}

não há dois grãos de poeira absolutamente idênticos, duas mãos que tenham os mesmos pontos notáveis, duas máquinas de escrever que tenham a mesma impressão, dois revólveres que estriem as suas balas da mesma maneira... Mas por que razão pressentimos que o problema não está bem situado enquanto procuramos nos factos o critério de um principium individuationis? É que uma diferença pode ser interna e não conceptual (DELEUZE, 2000, p. 78, grifos do autor).

De acordo com as palavras de Deleuze (2000) acima, há uma clara compreensão sobre a ideia de que a diferença “pode ser interna”, o que significa colocar em xeque a universalização das singularidades, responsável pelo enquadramento dos sujeitos em categorias reconhecíveis e fixas que desconsiderariam as múltiplas formas de existência humana. A partir disso, cabe indagar: quais categoriais e classificações vêm se constituindo e se legitimando nos cotidianos escolares? E quais as categoriais e classificações que silenciam/negam os vários modos de existências dos jovens? Como explorar e trabalhar, com os jovens e seus professores, a "diferença interna”?

A sexualidade é um tema que perpassa o cotidiano escolar, abarca o interesse dos jovens, mas geralmente é pouco explorado ou simplesmente ignorado pelas práticas pedagógicas. Entretanto, mesmo aparentemente ausente no trabalho em sala de aula, a concepção que professores e seus alunos apresentam sobre gênero e sexualidade pode ser percebida por meio da linguagem (LOURO, 2011), que carrega e institui discursos muitas vezes em sintonia com a linha de pensamento da heteronormatividade. Além disso, conforme Louro (2011, p. 69, grifos meus) argumenta, “a linguagem não apenas expressa relações, poderes, lugares, ela os institui; ela não apenas veicula, mas produz e pretende fixar diferenças". Como exercício permanente de reflexão e problematização, parece mais do que necessário 


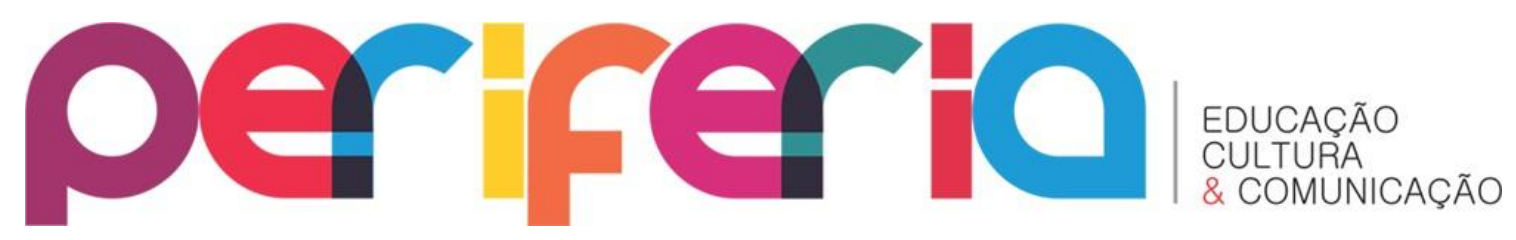

estarmos atentos às diversas formas com as quais utilizamos a linguagem no cotidiano escolar, promovendo formas de suprimir a incidência de discursos preconceituosas e discriminatórias contra aqueles que não se identificam com o modelo da matriz heterossexual.

A partir do relato de Nectar, pensar uma educação com a diferença é reconhecer a necessidade de transformar, em "mares de rosas", o "Calvário" que muitos sujeitos enfrentam cotidianamente, na esperança de que seja contestada a produção de uma diferença que identifica os sujeitos queer ("estranhos", "esquisitos") como "anormais". No papel de educador, acredito ser imprescindível pensar uma educação com a diferença com o objetivo de colocar em xeque a produção de uma suposta "normalidade" que apenas reforça estereótipos e representações que descaracterizam e desqualificam determinadas formas de viver e de explorar os desejos e os prazeres corporais.

\section{REFERÊNCIAS}

BACCHETTA, P. Co-formações / co-produções: considerações sobre poder, sujeitos subalternos, movimentos sociais e resistência. In: TORNUIST, C. S.; COELHO, C. C.; LAGO, M. C. de S.; LISBOA, T. K. (Orgs.). Leituras de resistência. Corpo, violência e poder. Vol. I. Florianópolis: Editora Mulheres, 2009, p. 49-74.

BAKHTIN, M. Estética da criação verbal. Tradução de Paulo Bezerra. 6. Ed. São Paulo: Martins Fontes, 2011.

BENTO, B. Na escola se aprende que a diferença faz a diferença. Estudos Feministas, Florianópolis, v. 19, n. 2, p. 549-559, maio/ago. 2011.

BEZERRA, P. Polifonia. In: BRAIT, B (Org.). Bakhtin: conceitos-chave. 5. Ed. São Paulo: Contexto, 2012, p. 191-200.

BHABHA, H. O local da cultura. Tradução de Myriam Ávila, Eliana Lourenço de Lima Reis e Gláucia Renate Gonçalves. Belo Horizonte: Editora UFMG, 1998.

BRITZMAN, D. O que é esta coisa chamada amor: identidade homossexual, educação e currículo. Revista Educação \& Realidade, Porto Alegre, v. 21, n. 1, p. 71-96, jan./jun. 1996. 


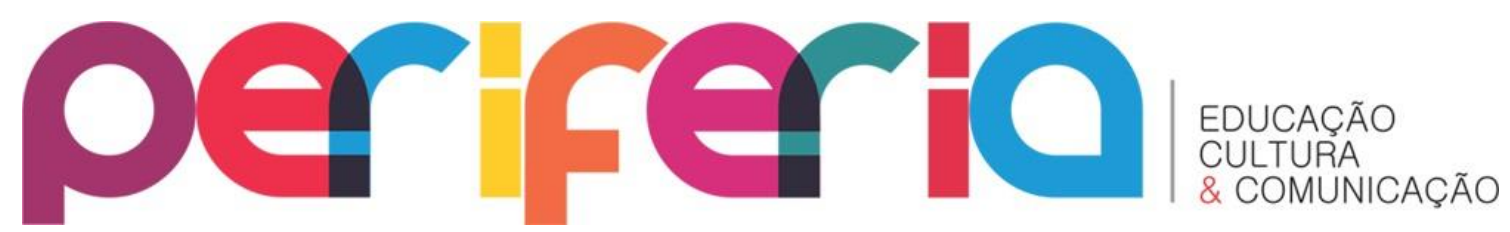

BUTLER, J. Critically queer. GLQ: A Journal of Lesbian and Gay Studies, v. 1, n. 1, p. 17-32, nov. 1993.

COUTO JUNIOR, D. R. Gênero, sexualidade e a teoria queer na educação: colocando em questão a heteronormatividade. Atos de Pesquisa em Educação, Blumenau, v. 11, n. 1, p. 250-270, jan./abr. 2016.

Relações entre gênero, sexualidade e família: "homem com homem dá lobisomem, mulher com mulher dá jacaré”. Revista Tecer, Belo Horizonte, v. 7, n. 13, p. 91-104, nov. 2014.

Etnografia virtual e as contribuições de Mikhail Bakhtin na Pesquisa com internautas. Revista Teias, Rio de Janeiro, v. 14, n. 31, p. 83-94, maio/ago. 2013.

COUTO JUNIOR, D. R.; OSWALD, M. L. M. B. "Tudo o que você disser vira pesquisa": trilhando caminhos teórico-metodológicos na pesquisa com internautas. Revista Teias, Rio de Janeiro, v. 17, p. 179-193, 2016.

COUTO JUNIOR, D. R.; FERREIRA, H. M. C.; OSWALD, M. L. M. B.

Compartilhando experiências sobre o "armário": as conversas online como procedimento metodológico da pesquisa histórico-cultural na cibercultura. In: SEMINÁRIO INTERNACIONAL REDES EDUCATIVAS E TECNOLOGIAS, 9., 2017, Rio de Janeiro. Anais... Rio de Janeiro: UERJ, 2017, 13p.

DELEUZE, G.s. Diferença e repetição. Tradução de Luiz Orlandi e Roberto Machado. Lisboa: Relógio D’Água Editores, 2000.

FOUCAULT, M. O sujeito e o poder. In: RABINOW, P.; DREYFUS, H. L. (Orgs.). Michel Foucault, uma trajetória filosófica: para além do estruturalismo e da hermenêutica. Tradução de Vera Porto Carrero. Rio de Janeiro: Forense Universitária, 1995, p. 231-249.

A ética do cuidado de si como prática da liberdade. In: MOTTA, M. B. (Org.) FOUCAULT, M. Coleção Ditos \& Escritos V. Ética, sexualidade, política. Tradução de Elisa Monteiro e Inês Autran Dourado Barbosa. Rio de Janeiro: Forense Universitária, 2004, p. 264-287.

. Friendship as a way of life. Tradução de John Johnston. In: RABINOW, P. (Org.). FOUCAULT, M. Ethics: subjectivity and truth - the essential works of Michel Foucault 1954-1984. Volume 1. New York: The New Press, 1997, p. 135-140.

GIL, J. Prefácio. In: DELEUZE, G. Diferença e repetição. Tradução de Luiz Orlandi e Roberto Machado. Lisboa: Relógio D’Água Editores, 2000, p. 9-29. 


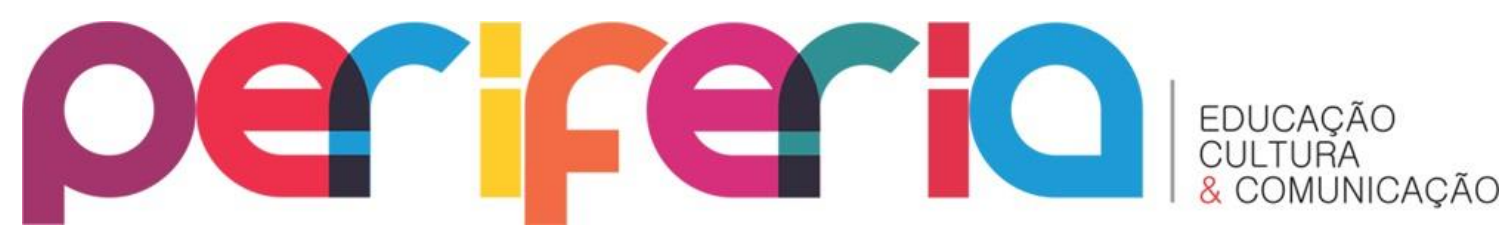

GUATTARI, F.; ROLNIK, S. Micropolítica: cartografias do desejo. 4. Ed. Petrópolis, RJ: Vozes, 1996.

LOURO, G. L. Um corpo estranho: ensaios sobre sexualidade e teoria queer. 2. Ed. Belo Horizonte: Autêntica, 2013.

. Gênero, sexualidade e educação: uma perspectiva pós-estruturalista.

12. Ed. Petrópolis, Rio de Janeiro: Vozes, 2011.

Foucault e os estudos queer. In: RAGO, Margareth; VEIGA-NETO, A. (Orgs. ). Para uma vida não-fascista. Belo Horizonte: Autêntica, 2009, p. 135143.

- Teoria queer - uma política pós-identitária para a educação. Revista Estudos Feministas, Florianópolis, v. 9, n. 2, p. 541-553, 2001.

MISKOLCI, R. Teoria Queer: um aprendizado pelas diferenças. 2. Ed. Belo Horizonte: Autêntica, 2013.

Não ao sexo rei: da estética da existência foucaultiana à política queer. In: SOUZA, L. A.; SABATINE, T. T.; MAGALHÃES, B. R. (Orgs.). Michel Foucault: sexualidade, corpo e direito. São Paulo: Cultura Acadêmica, 2011, p. 47-68.

. Do desvio às diferenças. Teoria \& Pesquisa, São Carlos, v. 47, n. 1, p. 9-41, jul./dez. 2005.

- A teoria queer e a sociologia: o desafio de uma analítica da normalização. Sociologias, Porto Alegre, ano 11, n. 21, p. 150-182, jan./jun. 2009.

PRECIADO, P. B. Quem defende a criança queer? Jangada, Viçosa, n. 1, p. 9699, jan./jun. 2013.

RANNIERY, T. No balanço da "teoria queer" em educação: silêncios, tensões e desafios. Sexualidad, Salud y Sociedad - Revista Latinoamericana, Rio de Janeiro, n. 25, p. 19-48, abr. 2017.

SEDGWICK, E. K. A epistemologia do armário. Cadernos Pagu, n. 28, p. 19-54, jan./jun. 2007.

SILVA, T. T. Documentos de Identidade: uma introdução às teorias do currículo. 2. Ed. Belo Horizonte: Autêntica, 2005.

A produção social da identidade e da diferença. In: SILVA, T. T.

(Org.). Identidade e diferença: a perspectiva dos Estudos Culturais. 13. Ed.

Petrópolis, RJ: Vozes, 2013, p. 73-102. 


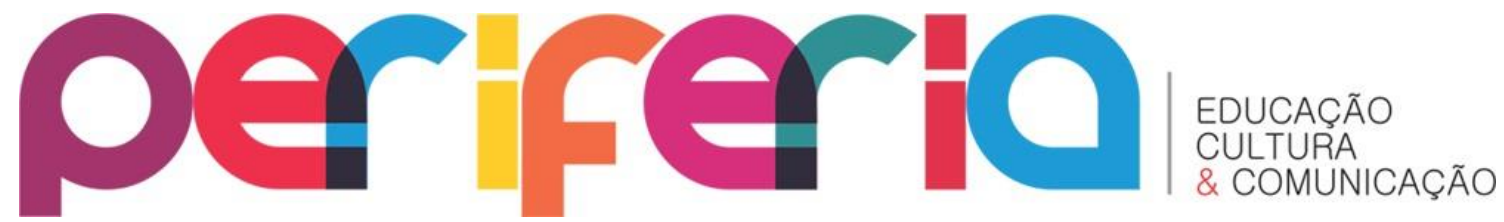

SOARES, M. da C. S. A produção da diferença no cotidiano das escolas: currículo, representação, significação e devir. In: RODRIGUES, A.; BARRETO, M. A. (Orgs.). Currículos, gêneros e sexualidades: experiências misturadas e compartilhadas. Vitória: Edufes, 2013, p. 83-102. 